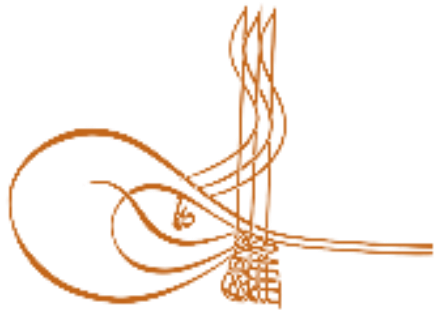

www.turkishstudies.net/social
Turkish Studies - Social Sciences

eISSN: $2667-5617$

Research Article / Araşttrma Makalesi

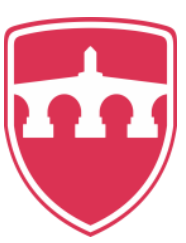

INTERNATIONAL

BALKAN

UNIVERSITY

Sponsored by IBU

\title{
Muhasebe Meslek Mensuplarının Çalışma Biçimlerine Göre; Genel İş Tatmini Ve İş Tatmini Alt Boyutlarının İncelenmesi
}

\author{
According to Accountants Working Forms; General Job Satisfaction and Investigation of Job \\ Satisfaction Sub-Dimensions
}

Osman Yilmaz

\begin{abstract}
Accountancy is a profession which is carried out individually and requires continuous intellectual activity in this process. As a result of the technological and telecommunication developments experienced as a result of the fourth industrial revolution, information storage and data processing capacity have increased; the way accountants do business and their approach to work have changed with easy access to and processing of information. Increasing expectations from the accounting department and professional accountants affects the motivation, performance and job satisfaction of the professionals. Achieving job satisfaction is important in terms of happiness, job motivation and job performances of professionals. Because of this importance, since its emergence, the concept of job satisfaction has been the subject of many researches and its relationship with many variables has been examined. In this study, it is aimed to determine whether behavioral consequences of job satisfaction of professional accountants differ in demographic characteristics, working time, expectations from work, working types of the members of the professions in order to contribute to the studies carried out to date. For this purpose, in this study, job satisfaction and internal and external dimensions of job satisfaction were examined, and it was analyzed whether it differed by ANOVA test by examining the differentiation and the direct effects of the differences of professional accountants on job satisfaction. According to the results of the study; It was determined that the participants' internal satisfaction and external satisfaction sub-dimension scores and job satisfaction scale scores were "medium level".
\end{abstract}

Structured Abstract: Expectations from the accountant profession based on industrial, technological and telecommunicational developments have increased; duties and responsibilities of accountants have increased at the same time (Yalçın, 2012: 114). Increasing expectations from the accounting department and accountants affects the performance and job satisfaction of accountants. Met job satisfaction is crucial in terms of motivation and job performance. The job satisfaction concept has been subjected to many studies and scrutinized in terms of its relationships with various variables.

\footnotetext{
* Dr. Öğr. Üyesi, Batman Üniversitesi, İktisadi ve İdari Bilimler Fakültesi, İşletme Bölümü Asst. Prof. Dr. Batman University, Faculty of Economics and Administrative Sciences, Department of Business ORCID 0000-0001-7512-5076

osmnylmz@hotmail.com
}

Cite as/ Atıf: Yılmaz, O. (2020). Muhasebe meslek mensuplarının çalışma biçimlerine göre; genel iş tatmini ve iş tatmini alt boyutlarının incelenmesi, Turkish Studies - Social, 15(2), 441-455. https://dx.doi.org/10.29228/TurkishStudies.40057

Received/Geliş: 08 December/Aralık 2019

Accepted/Kabul: 25 February/Şubat 2020

Copyright $($ INTAC LTD, Turkey

Checked by plagiarism software Published/Yayın: 29 February/Şubat 2020 CC BY-NC 4.0 
This study aimed to contribute to available studies and determine whether job satisfaction behavioral results vary by their demographic characteristics, working hours, expectations from the job, manner of work.

The accountant is a member of a profession who has duties toward government, society, professional organization, customers, employees and himself. Accountantship profession is the professional activities that are performed within the scope of laws and professional legislation by the experience arising from education and practice (Arıkan, 2009: 10).

Accountantship profession has to keep its prestige and reliability as required by the mission; accountants should care to provide this. Just as being in other professions, accountantship has occupational problems such as running into contraction about standards of judgment, conflicts in rules and decisions. An accountant has to tell the truth, be honest and modest despite all these problems. In addition to this, members of the accounting profession should respect the laws and regulations of professional organizations (Yalçın, 2011: 48).

Candidate of members of the profession, too, have special problems related to the process. First of all, there is a probation period of 3 years before occupational ownership. In this process, the candidate passes the exam first to intern to increase his knowledge and awareness of the profession (Uzay, 2005: 71). This process includes backbreaking exams and internship calendar that cannot be seen in any profession beginning. Moreover, this is a costly process at the same time.

Job satisfaction is one of the issues that are mostly studied within the context of organizational psychology (Judge and Church, 2000). Job satisfaction is delightedness that is felt as the result of job and experiences related to the job (Y1lmaz, Şahin, 2019: 504). Competition and pressure in business life trigger job dissatisfaction. Again, job dissatisfaction causes chronic fatigue, delirium, tedium, negligence, poor work quality, general underperformance and finally resignation (Yazıcıŏlu, 2010: 245).

Low job satisfaction causes poor loyalty to the organization, occupational burnout, impairment of mental and physical health and poor personal satisfaction (Özkan and Özdevecioğlu, 2011: 206).

Since we have budget and time constraints, this study was performed by applying a convenience survey method to reachable persons via portals in which independent accountants and financial advisors are enrolled via social media. The related survey was also applied to candidate of members of the profession and members of Adana, Mersin, Batman Chamber of Financial Advisors

As is seen below, the total main sample consisted of 5.632 persons.

\begin{tabular}{|l|r|r|}
\hline & \multicolumn{2}{|l|}{$\begin{array}{l}\text { Independent Accountant and } \\
\text { Financial Advisors (IAFA) }\end{array}$} \\
\hline Siirt /Batman & 190 & Candidate \\
\hline Mersin & 1.997 & 438 \\
\hline Adana & 2.336 & 621 \\
\hline
\end{tabular}

Survey form including three parts was utilized as the data collection tool. Demographic information form consists of gender, age, educational background, marital status, province, manner of work (IAFA, IAFA candidate) information of the participants.

The second part of the survey form includes the Minnesota Job Satisfaction Scale that was developed by Weiss et al. (1967) and adapted to Turkish by Baycan (1985) by conducting reliability and validity studies. The related scale is in the form of a five-point Likert scale; there were 20 items and 2 dimensions (intrinsic satisfaction, extrinsic satisfaction). All the expressions in scale were reversely coded; high score means high job satisfaction. Cronbach Alpha coefficient was 0,96; Cronbach Alpha coefficients of sub-dimensions respectively were 0,93 and 0,90 .

There can be seen the information form in which the variables of 'career opportunities, personal development, corporate identity, and salary' are aligned in order of priorities in the third part of the survey.

SPSS 21.0 program was used in the analysis of data. Demographic information of participants was shown by frequency and percentage table; scale and sub-dimension scores were shown by mean, standard 
deviation and coefficient of skewness. Coefficient of skewness that is used in normal distribution position of scores of a continuous variable remains in \pm 1 borders; this can be commented that scores do not display a significant deviation more than the normal distribution (Büyüköztürk, 2011). Since it was found that scale and sub-dimension scores show the normal distribution in the test of normality, an independent two-sample t-test was utilized in comparing scores based on gender, marital status, educational background and manner of work; ANOVA test was used in comparison based on age groups and working time as IAFA. Confidence interval in analyses was specified as $95 \%$ (significance level $0,05 \mathrm{p}<0,05$ ).

For research findings, intrinsic and extrinsic satisfaction sub-dimension scores and job satisfaction scale scores are at 'medium level'.

This study examined the job satisfaction levels and differentiation of IAFA and IAFA candidates. Moreover, we also tested whether there is a differentiation in terms of other demographic factors.

Intrinsic and extrinsic satisfaction levels of participants do not vary by gender. Much as there are studies related to the effectiveness of gender on job satisfaction, results in the direction of these effects are inconsistent (Baş and Ardıç, 2005).

Regarding marital status, extrinsic satisfaction and job satisfaction scores are significantly higher in married participants compared to single ones. Much as it is thought that this situation is rooted in age, we need to associate it with different reasons because there is no difference based on the age groups. For Telman and Ünsal (2004), the satisfaction level of married participants reflects a job and changes their extrinsic expectations related to the job. There is not a significant difference based on marital status in terms of intrinsic satisfaction.

With reference to the results of the ANOVA test that was applied for comparing job satisfaction and sub-dimension scores based on age groups, educational background, and manner of work; job satisfaction scale and sub-dimension scores do not show a significant difference.

Michigan University conducted studies in different countries and found that job satisfaction is higher based on increasing age (Davis, 1984: 99). It is expected that job satisfaction of accountants should increase based on the increase in earning and working time with the linear relationship between working time and age (Aktaş and Aktaş, 1991:78). Income differences arising from age and experience are accepted as normal because of the expectation that the income of accountants increases based on age. This accepted mentality does not cause differentiation in job satisfaction.

Bilgiç (1998) made a research and found no difference between educational background and job satisfaction. Burris (1983) talked about job satisfaction arising from the difference between the educational background and qualifications of workers. For him, there are educational standards in accord with the qualification of the job; this situation explains the difference in job satisfaction by the reason of the balance between job and educational background.

Organizations need to provide job satisfaction (Mert et al., 2019). Government, just as being in developed countries, should provide and keep the prestige of accountants who function as a bridge between itself and taxpayers. Complicated legislation makes difficulties to be followed by members of the profession and causes misunderstanding fiscal legislation and delays in tax applications. Simplifying the fiscal legislation ensures tax revenues to increase; personnel expenses to be saved by minimizing bureaucratic processes. Besides, by this means, job satisfaction level of accountants who are the most important partners of the government in taxation increases.

Chamber of Financial Advisors should help to overcome the difficulties of the complexity and constant change of legislation; they also should provide training and applications related to updates to be used by members by user-friendly solutions. Positive discrimination for low-income members of the profession and new members of the profession increases the prestige of the accountantship.

It should also be provided for candidates to overcome the difficulties in the internship period; develop in the profession and receive a satisfactory salary.

Keywords: Management, Job Stress, Job Satisfaction, Job Performance, professional accountant 
Öz: Muhasebecilik, bireysel olarak icra edilen ve bu süreçte ve sürekli düşünsel faaliyet gerektiren bir meslektir. Dördüncü sanayi devrimi sonucunda yaşanan teknolojik ve telekominikasyonel gelişmelere bağli olarak bilgi depolama ve veri işleme kapasitesi artmış, bilgiye ulaşma ve bilgiyi işlemenin kolaylaşması ile muhasebecilerin iş yapma biçimleri ve işe olan yaklaşımlarda değişim yaşanmaktadır. Muhasebe departmanı ve muhasebe meslek mensuplarından beklentilerin artması meslek mensuplarını motivasyonlarını performansları ve iş tatminini etkilemektedir. İş tatmininin gerçekleştirilmesi; meslek mensuplarının mutluluğu, işe yönelik motivasyonları ve iş performansları bakımından önemlidir. Bu önemi dolayısı ile iş tatmini kavramı ortaya çıkışından bugüne birçok araştırmaya konu olmuş çok sayıda değişken ile ilişkisi incelenmiştir. Bu çalışmada; bugüne kadar yapılmış çalışmalara katkı sağlamak üzere, muhasebe meslek mensuplarının işe yönelik iş tatmini davranışsal sonuçlarının meslek mensuplarının demografik özellikleri, çalışma süreleri, işten beklentileri, çalışma şekilleri bakımından farklılaşıp farklılaşmadığını tespit etmek amaçlanmıştır. Bu amaçla, bu çalışmada iş tatmini ve iş tatmininin içsel ve dışsal boyutları, incelenerek bu tatmin olma durumuna muhasebe meslek mensuplarının farklılıklarının iş tatmini üzerindeki doğrudan etkileri ve farklılaşmaları incelenerek farklılık gösterip göstermediği ANOVA testi ile analiz edilmiştir. Çalışma sonuçlarına göre; katılımcıların içsel tatmin ve dışsal tatmin alt boyut puanları ve iş tatmini ölçek puanlarının "orta düzeyde" olduğu tespit edilmiştir.

Anahtar Kelimeler: Yönetim, İşletme, İş Stresi, İş performansı, İş Tatmini, Muhasebe Meslek Mensubu

\section{Giriş}

Muhasebe mesleği bir işletmenin mali tüm olayları ile ilgili olup, verilerin toplanması, işlenmesi, sınıflandırılması, raporlanması ve analiz edilmesi yoluyla işletmenin amaçlarını gerçekleştirilmesine yönelik performans değerleme, karar alma ve uygulama süreçlerine yardımcı olur. Yaşanan ekonomik ve teknolojik gelişmeler muhasebecilik mesleğini ve bu meslekten beklentileri arttırmış (Yalçın, 2012: 114), muhasebe bilgisinin bu bilgiye ihtiyacı olanlara iletilmesi milli kaynakların verimli ve etkili olarak kullamına açısından önemlidir. Bu nedenle muhasebecilerin ulusal ve uluslararası yasalarla birlikte genel kabul görmüş muhasebe ilkelerine tüm muhasebe süreçlerinde uyması gerekliliğini ortaya çıkarır (Kısakürek ve Alpan, 2010: 213-214).

$\mathrm{Bu}$ süreçte işletme adına vergi sorumluluklarının da yerine getirilmesinden aracı sorumlu olarak sorumludur. Kamu ve özel kuruluşlara finansal raporlamaların yapılması gerekmektedir. Altun ve Gedikoğlu, 2016: 238). Bu süreçte devletin alacağ1 vergi benzeri ödemelerin hesaplanmas1 ve ödemesine aracılık yapılması süreçlerinde kamu otoritesi ve mükellefin beklentileri arasında kalmaktadır. Mükellef tarafından kamu hizmetinin yapılmasına aracı olarak görülen muhasebecinin hizmeti takdir görmemekte ekstra külfet olarak değerlendirilmektedir (Hacıhasanoğlu ve Karaca, 2014: 157).

Yapılan araştırma sonuçlarına göre muhasebe meslek mensupları açısından en önemli sorunların; haksız rekabet, tahsilat problemi ve mevzuatın karmaşıklığı ile beraber sık sık değişmesi olduğu görülmektedir. Yereli (2006) ve Bilen (2008)'in araştırmalarına göre; artan meslek mensubu sayısına bağlı olarak rekabetin artması sonucunda yeterli müşteri bulabilmek ve bir müşteriden yeterince para kazanmada yaşanan güçlük, işe ve işten yaşanan tatmin düzeyine yansımaktadır (Nalbantoğlu, 2003). İş tatmini, bireylerin işi ile ilgili algıları deneyimleri ve hissettiklerinin kendi içerisinde değerlendirilmesi sonucunda memnun olması, pozitif duygular beslemesidir. Meslek mensuplarının bu duygularının sonuçları üzerindeki olası etkileri dolayısıyla iş tatmininin araştırılması önemli olduğu değerlendirilmektedir (Adegoke vd., 2015: 947). İş tatminini veya tatminsizliğini, istihdam modelleri, demografik unsurlar, iş çevresi, bireysel faktörler ve kurumsal faktörler, Demografik özellikler, istihdam modelleri, kurumsal faktörler, bireysel farklılıklar ve iş çevresi gibi unsurlar tek başına, birlikte ve/veya karmaşı etkileşim ile etkileyen faktörlerdir (Belias vd., 2015: 325). 


\section{Kavramsal Çerçeve}

\subsection{Muhasebe Mesleği ve Meslek Mensupları}

Muhasebecinin; kamuya, SMMM odasına, çalışanlarına, müşterilerine ve kendine karsı farklı sorumlulukları vardır. Muhasebecilik mesleği ise alınan eğitim ve uygulamadan edinilen tecrübe ile yasalar ve mesleki mevzuat çerçevesinde gerçekleştirilen profesyonel faaliyetlerdir (Arıkan, 2009: 10).

1989 y1lında yürürlüğe girmiş olan 3568 Sayılı kanunda muhasebecilik mesleği;

1) Serbest Muhasebeci, (SM)

2) Serbest Muhasebeci Mali Müşavir, (SMMM)

3) Yeminli Mali Müşavir. (YMM)

olmak üzere üç statüde belirtmiştir (Kutlu, 2008: 145), 5786 sayılı kanun ile serbest muhasebecilik SMMM'liğe dönüştürülmüştür (Şengel, 2011: 169-170).

Muhasebecilik mesleği işletmelerin mali konularda ihtiyaç duyduğu bilgileri temin edebilmek için ispatlayıcı evrakları derleyen, kaydederek veriye dönüştüren, bu verileri sistematik olarak sınıflandıran, özetleyen, analiz ederek işletmenin ve diğer paydaşların kullanımına sunan bir meslektir. Bu bilgilerin standardı, muhasebeye biçilen misyona ve muhasebe departmanının yeteneklerine bağlıdır (Kaygusuzoğlu ve Uluyol, 2011: 300).

Muhasebe mesleği işletmelerin yanı sıra devletler için de çok önemlidir. 5 bin yıllık bir geçmişe sahip olan muhasebe mesleği yaşanan teknolojik gelişmelerin de katkısı ile kamu ve işletmeler arasında bilgi trafiğini sağlamaktadır. Bu ilişkinin açık ve tarafsız olarak yönetilebilmesi bu bilgilere dayalı doğru ve zamanında karar alınabilmesi düzgün işleyen muhasebe sistemine bağlıdır.

Muhasebe mesleği üstlendikleri misyon gereği saygınlığını ve güvenirliğini korumak durumundadır. Muhasebe meslek mensupları bunu sağlamak için gerekli özeni göstermelidir. Muhasebe mesleği diğer meslekler gibi, kendi içerisinde çelişkiler barındırır. Bu çelişkiler sonucunda kuralların ve kararların anlaşılmasında farklı değerlendirmelerin olması önemli bir mesleki problemdir. Fakat bu çelişkiler içerisinde; muhasebe mesleği mensubunun ortalama ahlaktan daha yüksek bir anlayış içerisinde, doğruyu, dürüst ve tutarlı olması zorunludur. Bu anlayış içerisinde hareket ederken aynı zamanda mevcut mevzuata ve mesleki düzenlemelere de uymak zorundadır (Yalçın, 2011: 48).

\subsection{Muhasebe Meslek Mensuplarmın Sorunları}

Günümüzde yaşanan teknolojik ve ekonomik gelişmelerden kaynaklı olarak örgüt yapılarında önemli değişimler yaşanmakta, örgütler daha karmaşık hale gelmekte ve bununla ilgili olarak da sürekli yönetmelik ve mevzuat değişimleri yaşanmaktadır. Mali mevzuatın ayrıntılı ve karmaşık olmasının yanında sürekli değişmesi ve uygulamadaki aksamalar meslek mensuplarını zorlamaktadır (Çınar ve Güney, 2012: 271).

Muhasebeciler mesleğe başlama sürecinde öncelikle staj yapmakla birlikte, sonrasında iki seçenek ile karşı karşıya kalmaktadır. Ya bağımsız SMMM olarak çalışacak ya da bir işyerinde maaşlı olarak -bağımlı- olarak çalışacaktır. Bağımsız olarak ve tatmin edici bir gelir ile çalışmak genel olarak istenen bir durum olmakla birlikte özellikle tarife dışı ücretlendirmeler haksız rekabete yol açmaktadır. Muhasebeci sayısındaki artış ile birlikte yaşanan rekabet ortamı muhasebecilik mesleğinin stresini ve yaşanan rekabeti arttırmaktadır (Dızman ve Güney, 2015: 98).

Haksız rekabet meslek mensuplarının tatmin edici gelir elde edilmesini engellemekte, bu da meslek mensuplarında iş tatminsizliği yaşamalarına neden olmaktadır (Demirkol, 2018: 19-38). 


\subsection{Aday Meslek Mensuplarının Sorunları}

S.M.M.M. stajını yapabilmek için gerekli süreç S.M.M.M. odası alt kurumu olan TÜRMOB aracılığı ile yürütülmektedir. Bu süreçte öncelikle staja başlama sınavını kazanarak stajın yapılması ile mesleğe ilişkin bilgi ve farkındalığın artması sağlanır (Uzay, 2005: 71).

Bu süreç Türkiye'de hiç bir meslek başlangıcında olmayan şekilde zorlu bir sınavları ve staj takvimini içermektedir. Aynı zamanda mali bakımdan da masraflı bir süreçtir

$\mathrm{Bu}$ süreçte aday meslek mensuplarının temel sorunları üç ana başlıkta toplanmaktadır. (Nalbantoğlu, 1997: 343):

1-Staj yeri bulma ve ücret sorunu: Staj yeri bulmak ve düşük ücretler ile çalışmak zorunda kalmaktadirlar.

2- Eğitim sorunu: Staj başlangıcı ve devamı için minimum lisans mezunu olmak şarttır ve yüksek lisans yapmak staj süresini bir yll azaltmaktadır. Staj süresince eğitim: zaman alıcı ve ekonomik külfeti vardır.

3-Yanında staj yapılan meslek mensubundan kaynaklanan sorunlar da söz konusudur. Meslek mensuplarının yetersizliği ve de özellikle iş yoğunluğuna bağl olarak staj süresinde gerekli gelişimi sağlayamamaktadırlar.

\section{4. İş Tatmini}

İş tatmini, örgütsel psikoloji kapsamında en çok çalışılan konulardandır (Judge ve Church, 2000). Tatmin duygusu öncü çalışmalarda motivasyon bağlamında incelenmiş olup bu bağlamdaki öncü çalışmalar; Gereksinimler Hiyerarşisi Yaklaşımı, Maslow (1943), Çift Faktör Teorisi, Herzberg (1966), Beklenti Teorisi, Vroom (1964)'dir. Bu çalışmalardan hareketle "iş modeli" Hackman ve Oldham (1980) ve "iş tatmin modelleri”" Price ve Mueller (1986) çalışmaları geliştirilmiştir.

İş tatmini, yapılan iş ve işe iliş̧kin deneyimlemeler sonucunda duyulan hoşnutluk halidir (Yılmaz, Şahin, 2019: 504). 1967 yılında Weiss, Dawis, England ve Lofquist tarafından geliştirilen Minnesota İş Tatmini Ölçeğine göre; iş tatminin, iç ve dış tatmin olmak üzere iki alt boyutu vardır. İçsel iş tatmini işe ilişkin duygusal etmenler; yeteneklerini sergileme ve geliştirme imkanları, işin kendisi, yetki, sorumluluk, kariyer imkanları gibi iş ile duygusal etkileşimler ve meslek hakkında hissettikleri... Dışsal iş tatmini ise; işletmenin fiziki koşulları, stratejisi, denetim şekli, ast-üst ilişkileri, iş yerindeki çalışma koşulları, ekonomik imkânlar gibi iş çevresi ve çalışanların işletmeyle ilişkin ne hissettiği ile ilgilidir. İşe yönelik tatmin arttıkça; motivasyon, etki, sorumluluk, işe devam, mesleki iletişim bakımından olumlu etkileri ile mesleki performansı içsel ve dışsal tatmin arttırıcı etki yapar (Hackman ve Oldham, 1975: 161). İş hayatında yaşanan rekabet, bask1, iş tatminsizliğini tetikler. İş tatminsizliği ise kronik yorgunluk, dalgınlık, bezginlik, işi savsaklama, işin kalitesinin düşmesine, genel performans düşüklüğüne ve sonuçta işin bırakılmasına yol açar. (Yazıcıoğlu, 2010: 245).

Muhasebe meslek mensuplarında iş tatmininin düşük olması örgüte bağl1lığın azalması, mesleki tükenmişlik, ruhsal ve fiziksel sağlığının bozulmasına ve kişisel tatmininin düşmesine neden olur (Özkan ve Özdevecioğlu, 2011: 206).

\section{Araştırmanın Tasarımı}

\subsection{Evren ve Örneklem}

Çalışmanın evreni bütçe ve zaman kısıtlarından dolayı kolayda anket yöntemi ile Adana, Mersin, Batman Mali müşavirler odası mensupları ve bunlara bağlı olarak staj yapan aday meslek mensuplarına ve sosyal medya aracılığı ile SMMM ve SMMM adaylarının üye olduğu portallar aracıllğ 
Muhasebe Meslek Mensuplarının Çalışma Biçimlerine Göre; Genel İş Tatmini ve İş Tatmini...447

\begin{tabular}{llc} 
SMMM & \multicolumn{2}{c}{ Stajyer } \\
Siirt /Batman & $: 190$ & 53 \\
Mersin & $: 1.997$ & 438 \\
Adana & $: 2.336$ & 621
\end{tabular}

Toplam ana örneklem yukarıda detayları verildiği üzere toplam 5.632 kişidir.

\subsection{Veri Toplama Aracı}

Araştırmada veri toplama aracı olarak üç bölümden oluşan anket formu kullanılmıştır. Veri toplama aracının ilk bölümünde katılımcıların cinsiyet, yaş, eğitim, medeni durum, çalıştığı il, çalışma şekli (SMMM, SMMM adayı) bilgilerinden oluşan demografik bilgi formu yer almaktadır.

Anket formunun ikinci bölümünde Weiss vd. (1967) tarafından geliştirilen ve Baycan (1985) tarafından Türkçe 'ye uyarlanarak güvenirlik ve geçerlik çalışmaları yapılan Minnesota İş Tatmini Ölçeği yer almaktadır. Ölçek beşli Likert tipinde (1-kesinlikle katıllyorum, 5-kesinlikle katılmıyorum) 20 madde ve 2 boyuttan (içsel tatmin, dışsal tatmin) oluşmaktadır. Ölçekteki ifadelerin tümü ters kodlanarak yüksek puan, iş tatmininin yüksek olduğunu ifade etmektedir. Bu çalışmada ölçeğin geneline ait Cronbach Alpha katsayısı 0,96; alt boyutların Cronbach Alpha katsayıları 0,93 ve 0,90 olarak tespit edilmiştir.

Anket formunun dördüncü bölümünde araştırmacı tarafından iş tatminini etkilediği düşünülen "kariyer olanakları, kişisel gelişim, kurumsal kimlik ve ücret" değişkenlerinin önem sırasına göre sıralandığı bilgi formu yer almaktadır.

\subsection{Araştırma Modeli ve Hipotezler}

$\mathrm{Bu}$ çalışmada muhasebe meslek mensupları ve mesleklerine ilişkin iş tatmin düzeyleri literatür çerçevesinde incelenmiş ve iş tatmin düzeyleri ve farklılaştırıcı unsurlar bağlamında hipotezler geliştirilmiş ve test edilmiştir. Bu hipotezler;

H1: Muhasebe Meslek Mensuplarının Işs Tatmini Düzeyleri Medeni Duruma Göre Farklılaşmaktadır.

H2: Muhasebe Meslek Mensuplarının İş Tatmini Düzeyleri Yaş Gruplarına Göre Farklılaşmaktadır.

H3: Muhasebe Meslek Mensuplarının İş Tatmini Düzeyleri Öğrenim Düzeyine Göre Farklılaşmaktadır.

H4: Muhasebe Meslek Mensuplarının İş Tatmini Düzeyleri Çalışma Süresine Göre Farklılaşmaktadır.

H5: Muhasebe Meslek Mensuplarının İş Tatmini Düzeyleri Çalışma Şekline Göre Farklılaşmaktadır.

\section{Analiz ve Sonuçlar}

\section{1. Ölçeklerin Geçerliliği ve Güvenilirliği}

Verilerin analizinde SPSS 21.0 programı kullanılmıştır. Katılımcıların demografik bilgileri frekans ve yüzde tablosuyla; ölçek ve alt boyut puanları ortalama, standart sapma ve çarpıklık katsayılarıyla gösterilmiştir. Ölçek puanları Çarpıklık (Skewness) katsayısı kullanılarak normallik sınamasına tabi tutulmuştur. Sürekli bir değişkenden elde edilen puanların normal dağılım özelliğinde kullanılan çarpıklık katsayısının (Skewness) \pm 1 sınırları içinde kalması puanların normal dağılımdan önemli bir sapma göstermediği şeklinde yorumlanabilir (Büyüköztürk, 2011). Yapılan normallik sınaması ile ölçek ve alt boyut puanlarının normal dağılım gösterdiği tespit edildiğinden 
puanların cinsiyet, medeni durum, eğitim düzeyi, çalışma şekline göre karşılaştırılmasında bağımsız iki örneklem t testinden; yaş gruplarına ve SMMM olarak çalışma süresine göre karşılaştırılmasında ANOVA testinden yararlanılmıştır. Analizlerde güven aralığ $\% 95$ (anlamlılık düzeyi $0,05 p<0,05$ ) olarak belirlenmiştir.

\subsection{Bulgular}

Tablo 1'de katılımcıların demografik özelliklerine göre frekans ve yüzde dağılımı gösterilmiştir.

Tablo 1: Katılımcıların Demografik Özelliklerine Göre Dağılımı

\begin{tabular}{|c|c|c|c|}
\hline Demografik Değiş̧ken & Gruplar & $\mathbf{n}$ & $\%$ \\
\hline \multirow{2}{*}{ Cinsiyet } & Kadın & 96 & 36,4 \\
\hline & Erkek & 168 & 63,6 \\
\hline \multirow{2}{*}{ Medeni durum } & Evli & 143 & 54,2 \\
\hline & Bekar & 121 & 45,8 \\
\hline \multirow{3}{*}{ Yaş } & 25 yaş ve altı & 40 & 15,2 \\
\hline & $26-35$ yaș & 139 & 52,7 \\
\hline & 36 yaş ve üstü & 85 & 32,2 \\
\hline \multirow{2}{*}{ Öğrenim düzeyi } & Üniversite & 176 & 66,7 \\
\hline & Lisansüstü & 88 & 33,3 \\
\hline \multirow{4}{*}{ SMMM olarak çalışma süresi } & 1 y1l ve daha az & 38 & 14,4 \\
\hline & $2-4$ y1l & 73 & 27,7 \\
\hline & 5-10 y1l & 80 & 30,3 \\
\hline & 11 yıl ve üstü & 73 & 27,7 \\
\hline \multirow{4}{*}{$\begin{array}{l}\text { İş tatminini etkileme açısından } \\
\text { önem sırası } \\
(1 . \text { sıradaki \%) }\end{array}$} & Kariyer olanakları & 85 & 26,0 \\
\hline & Kişisel gelişim olanakları & 80 & 24,5 \\
\hline & Kurumsal kimlik & 73 & 22,3 \\
\hline & Ücret & 89 & 27,2 \\
\hline \multirow{3}{*}{ Çalışma şekli } & Aday SMMM & 157 & 59,5 \\
\hline & Bağlı SMMM & 35 & 13,3 \\
\hline & Bağımsız SMMM & 72 & 27,2 \\
\hline \multirow{2}{*}{ Çalışma şekli } & Aday SMMM & 157 & 59,5 \\
\hline & SMMM & 107 & 40,5 \\
\hline
\end{tabular}

Araştırmaya katılan 264 SMMM ve SMMM adayının \%36,4'ü kadın, \%63,6'sı erkektir. Katılımcıların \%54,2'si evli, \%45,8'i bekardır. Katılımcıların \%15,2'si 25 yaş ve altı, \%52,7'si 2635 yaş, \%32,2'si 36 yaş ve üstüdür. Katılımcıların \%66,7'si üniversite, \%33,3'ü lisansüstü düzeyde öğrenim görmüştür. Katılımcıların \%66,7'si üniversite (ön lisans ve lisans), \%33,3'ü lisansüstü düzeyde öğrenim görmüştür. Katılımcıların \%14,4'ünün SMMM olarak çalışma süresi 1 yıl ve daha az, \%27,7'sinin 2-4 yı1, \%30,3'ünün 5-10 yıl, \%27,7'sinin 11 yıl ve üstüdür. İş tatminini etkileyen kavramlar önem sırasına göre ücret $(\% 27,2)$, kariyer $(\% 26,0)$, kişisel gelişim $(\% 24,5)$ ve kurumsal kimlik $(\% 22,3)$ olarak sıralanmıştır. Katılımcıların \%59,5'i SMMM adayı, \%13,3’ü bağlı SMMM, \%27,2'si bağımsız SMMM'dir. Katılımcıların \%59,5'i SMMM adayı, \%40,5'i SMMM'dir.

Tablo 2'de ölçek ve alt boyutlarının ortalama, standart sapma ve çarpıklık (Skewness) bilgilerinden oluşan betimsel istatistiklerine yer verilmiş̧ir. 
Muhasebe Meslek Mensuplarının Çalışma Biçimlerine Göre; Genel İş Tatmini ve İş Tatmini...449

Tablo 2.:Ölçeğe Ait Betimsel İstatistikler

\begin{tabular}{lcccc}
\hline Alt Boyut & $\mathbf{n}$ & $\overline{\mathbf{X}}$ & $\mathbf{S S}$ & Skewness \\
\hline İçsel Tatmin & 264 & 3,17 & 0,96 & $-0,14$ \\
Dişsal Tatmin & 264 & 2,95 & 1,04 & 0,04 \\
IŞ TATMiNì & 264 & 3,10 & 0,96 & $-0,11$ \\
\hline
\end{tabular}

Katılımcıların içsel tatmin $(3,17 \pm 0,96)$ ve dışsal tatmin $(2,95 \pm 1,04)$ alt boyut puanları ve iş tatmini ölçek puanlarının $(3,10 \pm 0,96)$ "orta düzeyde" olduğu tespit edilmiştir tespit edilmiştir (Ölçek ve alt boyutlardan alınabilecek en düşük (1) ve en yüksek (5) puanlara göre düzey aralıkları 5$1=4 / 5=0,80$; 1,00-1,80: "çok düşük"; 1,81-2,60: "düşük"; 2,61-3,40: "orta"; 3,41-4,20: "yüksek"; 4,21-5,00: “çok yüksek”).

Tablo 3'te iş tatmini puanlarının cinsiyete göre karşılaştırılmasına ait bağımsız iki örneklem $\mathrm{t}$ testi sonuçlarına yer verilmiştir.

Tablo 3: İş Tatmini Puanlarının Cinsiyete Göre Karşılaştırılması

\begin{tabular}{|c|c|c|c|c|c|c|}
\hline Alt Boyutlar & Cinsiyet & $\mathbf{n}$ & $\overline{\mathbf{X}}$ & SS & $\mathrm{t}$ & $\mathbf{p}$ \\
\hline İçsel Tatmin & $\begin{array}{l}\text { Kadın } \\
\text { Erkek }\end{array}$ & $\begin{array}{c}96 \\
168\end{array}$ & $\begin{array}{l}3,10 \\
3,21\end{array}$ & $\begin{array}{l}1,06 \\
0,91\end{array}$ & $-0,86$ & 0,388 \\
\hline Dışsal Tatmin & $\begin{array}{l}\text { Kadın } \\
\text { Erkek }\end{array}$ & $\begin{array}{c}96 \\
168\end{array}$ & $\begin{array}{l}2,82 \\
3,03\end{array}$ & $\begin{array}{l}1,10 \\
1,01\end{array}$ & $-1,54$ & 0,125 \\
\hline İŞ TATMINII & $\begin{array}{l}\text { Kadın } \\
\text { Erkek }\end{array}$ & $\begin{array}{c}96 \\
168 \\
\end{array}$ & $\begin{array}{l}3,00 \\
3,15 \\
\end{array}$ & $\begin{array}{l}1,04 \\
0,91\end{array}$ & $-1,22$ & 0,222 \\
\hline
\end{tabular}

İş tatmini ölçek ve alt boyut puanlarının cinsiyete göre anlamlı farklılık göstermediği $(\mathrm{p}>0,05)$ tespit edilmiştir.

Tablo 4'te iş tatmini puanlarının medeni duruma göre karşılaştırılmasına ait bağımsız iki örneklem $t$ testi sonuçlarına yer verilmiştir.

Tablo 4: İş Tatmini Puanlarının Medeni Duruma Göre Karşılaştırılması

\begin{tabular}{|c|c|c|c|c|c|c|}
\hline Alt Boyutlar & $\begin{array}{l}\text { Medeni } \\
\text { Durum }\end{array}$ & $\mathbf{n}$ & $\overline{\mathbf{X}}$ & SS & $\mathbf{t}$ & $\mathbf{p}$ \\
\hline \multirow{2}{*}{ İçsel Tatmin } & Evli & 143 & 3,28 & 0,94 & \multirow{2}{*}{1,96} & \multirow{2}{*}{0,051} \\
\hline & Bekar & 121 & 3,05 & 0,99 & & \\
\hline Dışsal Tatmin & Evli & 143 & 3,11 & 1,04 & 2,64 & 0,009 \\
\hline \multirow{2}{*}{ İŞ TATMINİ } & Evli & 143 & 3,23 & 0,94 & \multirow[b]{2}{*}{2,40} & \multirow{2}{*}{0,017} \\
\hline & Bekar & 121 & 2,94 & 0,98 & & \\
\hline
\end{tabular}

İçsel tatmin alt boyut puanlarının medeni duruma göre anlamlı farklılık göstermediği ( $>0,05)$ tespit edilmiştir.

Dışsal tatmin alt boyutu $(t=2,64 ; p<0,05)$ ve iş tatmini ölçeği $(t=2,40 ; p<0,05)$ puanlarının medeni duruma göre anlamlı farklılık gösterdiği tespit edilmiştir. Evli katılımcıların dışsal tatmin ve iş tatmini puanları, bekar katılımcıların puanlarına göre anlamlı düzeyde daha yüksektir.

Tablo 5'te iş tatmini puanlarının yaş gruplarına göre karşılaştırılmasına ait ANOVA (tek yönlü varyans analizi) testi sonuçlarına yer verilmiştir. 
Tablo 5: İ̧̧ Tatmini Puanlarının Yaş Gruplarına Göre Karşılaştırılması

\begin{tabular}{lcccccc}
\hline Alt Boyutlar & Yaş Grupları & $\mathbf{n}$ & $\overline{\mathbf{X}}$ & $\mathbf{S S}$ & $\mathbf{F}$ & $\mathbf{p}$ \\
\hline \multirow{3}{*}{ İçsel Tatmin } & A-25 yaş ve altı & 40 & 3,31 & 0,86 & & \\
& B-26-35 yaş & 139 & 3,17 & 0,91 & 0,56 & 0,569 \\
& C-36 yaş ve üstü & 85 & 3,11 & 1,10 & & \\
\hline \multirow{3}{*}{ Dişsal Tatmin } & A-25 yaş ve altı & 40 & 3,05 & 0,91 & & \\
& B-26-35 yaş & 139 & 2,94 & 1,01 & 0,20 & 0,816 \\
& C-36 yaş ve üstü & 85 & 2,93 & 1,16 & & \\
\hline \multirow{3}{*}{ IŞ TATMiNi } & A-25 yaş ve altı & 40 & 3,23 & 0,81 & & \\
& B-26-35 yaş & 139 & 3,08 & 0,92 & 0,43 & 0,651 \\
& C-36 yaş ve üstü & 85 & 3,06 & 1,10 & & \\
\hline
\end{tabular}

İş tatmini ölçek ve alt boyut puanlarının yaş gruplarına göre anlamlı farklılık göstermediği ( $>>0,05)$ tespit edilmiştir.

Tablo 6'da iş tatmini puanlarının öğrenim düzeyine göre karşılaştırılmasına ait bağımsız iki örneklem $\mathrm{t}$ testi sonuçlarına yer verilmiştir.

Tablo 6: İş Tatmini Puanlarının Öğrenim Düzeyine Göre Karşılaş̧ırılması

\begin{tabular}{|c|c|c|c|c|c|c|}
\hline Alt Boyutlar & Öğrenim Düzeyi & $\mathbf{n}$ & $\overline{\mathbf{X}}$ & SS & $\mathbf{t}$ & p \\
\hline İçsel Tatmin & $\begin{array}{l}\text { Üniversite } \\
\text { Iisansïstï }\end{array}$ & $\begin{array}{l}176 \\
88\end{array}$ & 3,13 & $\begin{array}{l}0,98 \\
0,06\end{array}$ & $-0,93$ & 0,354 \\
\hline Dışsal Tatmin & $\begin{array}{l}\text { Üniversite } \\
\text { Lisansüstü }\end{array}$ & $\begin{array}{l}00 \\
176 \\
88\end{array}$ & $\begin{array}{l}2,2 J \\
2,91 \\
3,03\end{array}$ & $\begin{array}{l}1,05 \\
1,03\end{array}$ & $-0,87$ & 0,385 \\
\hline İŞ TATMİNi & $\begin{array}{l}\text { Üniversite } \\
\text { Lisansüstü }\end{array}$ & $\begin{array}{l}176 \\
88 \\
\end{array}$ & $\begin{array}{l}3,05 \\
3,18 \\
\end{array}$ & $\begin{array}{l}0,97 \\
0,95 \\
\end{array}$ & $-1,00$ & 0,317 \\
\hline
\end{tabular}

İş tatmini ölçek ve alt boyut puanlarının öğrenim düzeyine göre anlamlı farklılık göstermediği $(p>0,05)$ tespit edilmiştir.

Tablo 7'de iş tatmini puanlarının çalışma süresine göre karşılaştırılmasına ait ANOVA (tek yönlü varyans analizi) testi sonuçlarına yer verilmiştir.

Tablo 7: İş Tatmini Puanlarının Çalışma Süresine Göre Karşılaştırılması

\begin{tabular}{|c|c|c|c|c|c|c|}
\hline Alt Boyutlar & Çalıșma Süresi & n & $\overline{\mathbf{X}}$ & SS & $\mathbf{F}$ & $\mathbf{p}$ \\
\hline \multirow{4}{*}{ İçsel Tatmin } & A-1 yll ve alt1 & 38 & 3,12 & 0,85 & \multirow{4}{*}{1,04} & \multirow{4}{*}{0,375} \\
\hline & B-2-4 y1l & 73 & 3,16 & 0,98 & & \\
\hline & C-5-10 y1l & 80 & 3,32 & 0,89 & & \\
\hline & D-11 yıl ve üstü & 73 & 3,05 & 1,10 & & \\
\hline \multirow{4}{*}{ Dışsal Tatmin } & A-1 y1l ve alt1 & 38 & 2,81 & 0,92 & \multirow{4}{*}{1,12} & \multirow{4}{*}{0,342} \\
\hline & B-2-4 y1l & 73 & 2,88 & 1,06 & & \\
\hline & C-5-10 y1l & 80 & 3,13 & 0,98 & & \\
\hline & D-11 yıl ve üstü & 73 & 2,91 & 1,14 & & \\
\hline \multirow{4}{*}{ İş TATMINII } & A-1 yıl ve alt1 & 38 & 3,02 & 0,85 & \multirow{4}{*}{1,11} & \multirow{4}{*}{0,346} \\
\hline & B-2-4 y1l & 73 & 3,06 & 0,97 & & \\
\hline & C-5-10 y1l & 80 & 3,26 & 0,89 & & \\
\hline & D-11 yıl ve üstü & 73 & 3,00 & 1,08 & & \\
\hline
\end{tabular}

İş tatmini ölçek ve alt boyut puanlarının çalışma süresine göre anlamlı farklılık göstermediği $(\mathrm{p}>0,05)$ tespit edilmiştir. 
Tablo 8'de iş tatmini puanlarının çalışma şekline göre karşılaştırılmasına ait bağımsız iki örneklem $\mathrm{t}$ testi sonuçlarına yer verilmiştir.

Tablo 8: İş Tatmini Puanlarının Çalışma Şekline Göre Karşılaştırılması

\begin{tabular}{|c|c|c|c|c|c|c|}
\hline Alt Boyutlar & Çalıșma Şekli & $\mathbf{n}$ & $\overline{\mathbf{x}}$ & SS & $\mathbf{t}$ & $\mathbf{p}$ \\
\hline İçsel Tatmin & $\begin{array}{l}\text { Aday SMMM } \\
\text { SMMM }\end{array}$ & $\begin{array}{l}157 \\
107\end{array}$ & $\begin{array}{l}3,16 \\
3,20\end{array}$ & $\begin{array}{l}0,95 \\
1,01\end{array}$ & $-0,32$ & 0,751 \\
\hline Dışsal Tatmin & $\begin{array}{c}\text { Aday SMMM } \\
\text { SMMM } \\
\end{array}$ & $\begin{array}{l}157 \\
107 \\
\end{array}$ & $\begin{array}{l}2,91 \\
3,01 \\
\end{array}$ & $\begin{array}{l}1,02 \\
1,08 \\
\end{array}$ & $-0,77$ & 0,442 \\
\hline İş TATMINİ & $\begin{array}{l}\text { Aday SMMM } \\
\text { SMMM }\end{array}$ & $\begin{array}{l}157 \\
107\end{array}$ & $\begin{array}{l}3,07 \\
3,14\end{array}$ & $\begin{array}{l}0,94 \\
1,00 \\
\end{array}$ & $-0,61$ & 0,544 \\
\hline
\end{tabular}

İş tatmini ölçek ve alt boyut puanlarının çalışma şekline göre anlamlı farklılık göstermediği $(\mathrm{p}>0,05)$ tespit edilmiştir.

Tablo 8'de iş tatmini puanlarının çalışma şekline göre karşılaştırılmasına ait ANOVA (tek yönlü varyans analizi) testi sonuçlarına yer verilmiştir.

Tablo 8: İş Tatmini Puanlarının Çalışma Şekline Göre Karşılaştırılması

\begin{tabular}{lcccccc}
\hline Alt Boyutlar & Çalışma Şekli & $\mathbf{n}$ & $\overline{\mathbf{X}}$ & $\mathbf{S S}$ & $\mathbf{F}$ & $\mathbf{p}$ \\
\hline \multirow{3}{*}{ İçsel Tatmin } & A-Aday & 157 & 3,16 & 0,95 & & \\
& B-Bağlı SMMM & 35 & 3,18 & 1,02 & 0,06 & 0,945 \\
& C-Bağımsız SMMM & 72 & 3,20 & 1,01 & & \\
\hline \multirow{2}{*}{ Dışsal Tatmin } & A-Aday & 157 & 2,91 & 1,02 & & \\
& B-Bağlı SMMM & 35 & 3,00 & 1,07 & 0,30 & 0,739 \\
& C-Bağımsız SMMM & 72 & 3,02 & 1,09 & & \\
\hline \multirow{2}{*}{ İ̧̧ TATMììi } & A-Aday & 157 & 3,07 & 0,94 & & \\
& B-Bağlı SMMM & 35 & 3,12 & 1,02 & 0,20 & 0,818 \\
& C-Bağımsız SMMM & 72 & 3,15 & 1,00 & & \\
\hline
\end{tabular}

İş tatmini ölçek ve alt boyut puanlarının çalışma şekline göre anlamlı farklılık göstermediği $(p>0,05)$ tespit edilmiştir.

\section{Sonuc}

$\mathrm{Bu}$ çalışmada, SMMM meslek mensupları ile ŞMMM adaylarının iş tatmin düzeylerini ve farklılaşmalarını incelemektedir. Aynı zamanda diğer demografik faktörler bakımından da farklılaşma olup olmadığına bakmaktadır.

157 aday SMMM ve 107 SMMM toplam 264 meslek mensubundan elde edilen verilerin analizinin sonucunda; katılımcıların içsel tatmin ve dışsal tatmin alt boyut puanları ve iş tatmini ölçek puanlarının "orta düzeyde" olduğu tespit edilmiştir. Katılımcıların içsel tatmin ve dışsal tatmin alt boyut puanları ve iş tatmini düzeyi cinsiyete göre farklılaşmamaktadır. Cinsiyetin iş tatmininde etkili olduğuna dair çalışmalar olmasına rağmen bu etkinin yönü konusundaki sonuçlar tutarsızdır (Baş ve Ardıç, 2005). Bu çalışma sonuçlarında muhasebe meslek mensuplarında cinsiyet değişkeninin farklılaşmaya sebep olmadığı görülmüştür.

Medeni duruma göre ise dışsal tatmin ve iş tatmini puanları evli katılımcılarda bekâr katılımcılara göre anlamlı düzeyde yüksektir. Bunun yaş ile ilgili olabileceği düşünülse de yaş gruplarına göre farklılık olmadığı görüldüğü için farklı sebeplere bağlamak gerekir. Telman ve Ünsal (2004)'a göre evlilerin aile yaşamındaki tatmin düzeyi işe yansımakta ve aynı zamanda iş ile ilgili dışsal beklentilerini değiştirmektedir. İçsel tatmin bakımından medeni duruma göre anlamlı bir farkl11ık görülmemektedir. 
İş tatmini ve alt boyut puanlarının yaş gruplarına, öğrenim düzeyine, çalışma sürelerine, çalışma şekillerine göre karşılaştırılması için yapılan ANOVA testi sonuçlarına göre İş tatmini ölçek ve alt boyut puanlarının anlamlı farklılık göstermediği tespit edilmiştir.

Michigan Üniversitesi tarafından farklı ülkelerde yapılan çalışmalar, yaşın artmasına bağlı iş doyumunun daha yüksek olduğunu bulmuştur (Davis, 1984: 99). Çalışanların çalışma süreleri ve yaşları arasındaki doğrusal ilişki ile birlikte muhasebe meslek mensuplarının çalışma süreleri il kazançlarının artışına bağlı olarak işe ilişkin doyumlarının yükselmesi beklenir (Aktaş ve Aktaş, 1991:78). Muhasebe meslek mensuplarında yaşa bağlı olarak gelirlerinin artacağına ilişkin beklenti olması nedeni ile yaşa ve tecrübeye bağlı getiri farklılaşmaları adil karşılanmakta ve iş tatmininde farklılaşmaya neden olmamaktadır.

Bilgiç'in (1998) çalışmasında eğitim düzeyi ile iş tatmini arasında bir farklılık olmadığını bulmuştur. Burris (1983)'in çalışmasında eğitim düzeyi ile yapılan işin nitelikleri arasında bir farklılık olması halinde iş tatminsizliğine yol açacağından bahseder ki: Muhasebe meslek mensupları için işin niteliğine uygun eğitim standartları vardır ve bu durum iş ile eğitim düzeyi arasında denge olması nedeni ile iş tatmininde farklılık olmasını açıklar.

İş tatminine ilişkin genel görünüm mesleğe ilişkin beklentilerin kısmen karşılandığı ancak işe ilişkin zorlukların da yaşanmakta oluşu ile ilgilidir. Bu durum her seviyede her yaş grubu, eğitim düzeyi ve iş tecrübesindeki meslek mensubu muhasebecilerde benzer şekillerde görülmektedir. $\mathrm{Bu}$ durumun düzelebilmesi için devlete, mali müşavirler odasına ve tüm meslek mensuplarına bazı sorumluluklar düşmektedir.

Örgütlerin kendisine çalışanların iş tatminini sağlaması gereklidir (Mert ve ark., 2019). Devlet; kendisi ile vergi mükellefleri arasında köprü görevi gören muhasebecilerin gelişmiş ülkelerde olduğu gibi saygınlığını sağlamalı ve korumalıdır. Gelir kaynağı olarak sadece muhasebesini tuttuğu şirketlere değil beyannamesini hazırladığı devlete de fatura kesmesini sağlayarak gelir bakımından sadece vergi mükelleflerine bağımlı olması durumu ortadan kaldırılmalıdır. Bu şekilde gelir tatminsizliğine bağlı haksız rekabetin ortadan kaldırılmasına katkı sağlayabilecektir.

Karmaşık mevzuat meslek mensuplarınca takip edilmesinde güçlük çıkarmakta, mali mevzuatın yanlış anlaşılmasına ve vergi uygulamalarında aksamalara neden olmaktadır. Mali mevzuatın, açık, net, anlaşılabilir şekilde yalınlaştırılması; devlet açısından vergi gelirlerinin artmasını, bürokratik proseslerin azaltılarak personel giderlerinden tasarruf edilmesini sağlayacak hem de vergi tahsilatında en önemli partnerleri olan muhasebe meslek mensuplarının iş tatmin düzeyini arttıracaktır.

Mali Müşavirler Odası (TÜRMOB)'da, mevzuatın karmaşıklığı ve sürekli değişimine yönelik sıkıntıların aşılmasına yardımcı olması ve güncellemelere ilişkin eğitim ve uygulamaların kullanıcı dostu çözümler ile üyelerine sunması gerekir. Haksız rekabeti azaltıcı önlemler almalı ve yaygınlaştırmalıdır. Bu yönde düşük gelirli meslek mensupları ile yeni meslek mensuplarına pozitif ayrımcılık yapması mesleğin saygınlığını arttıracaktır.

Aday meslek mensuplarının staj döneminde yaşadıkları, staj imkânı bulmaktaki sıkıntıları, mesleki bakımdan geliştirilmeleri ve tatmin edici maaş alması sağlanmalıdır.

$\mathrm{Bu}$ sonuçlar muhasebe meslek mensupları bağlanımda açıklayıcı olmakla birlikte bazı kısıtları söz konusudur. Çalışma seçili bazı odalar ve tesadüfi örneklemden farklı örneklem ile yapılarak daha açıklayıcı sonuçlara ulaşılabilir. Farklı meslek gruplarına uygulanarak desteklenebilir. 
Muhasebe Meslek Mensuplarının Çalışma Biçimlerine Göre; Genel İş Tatmini ve İş Tatmini...453

\section{Kaynakça}

Adegoke, A. A., Atiyaye, F. B., Abubakar, A. S., Auta, A., \& Aboda, A. (2015). Job Satisfaction and Retention of Midwives in Rural Nigeria. Midwifery, 31(10), 946-956. https://doi.org/10.1016/j.midw.2015.06.010

Aktaş, R., \& Aktaş, A. (1991). Uzmanlaşma, Yazılı Kurallar ve Yerinden Yönetimin İş Doyumu Üzerinde Etkisi. Verimlilik Dergisi, (2), 73-108.

Altun, A., \& Gedikoglu, I. G. (2016). SMMM Muhasebe Hizmet Sözleşmelerinde Tahsilatın Gerçekleşmemesi Halinde Yeni Bir Öneri Olarak Bildirimsiz (Otomatik) Fesih Müessesesi. Mali Çözüm Dergisi, 26, 237.

Arıkan, Y. (2009). Muhasebe Mesleğinde Uzmanlaşma ve Kurumsallaşma Süreci. Mali Çözüm Dergisi, 9-17.

Baş, T., \& Ardıç, K. (2005). Kamu ve vakıf üniversitelerindeki akademik personelin iş tatmin düzeyinin karşılaştırılması.

Baycan, A. (1985). An Analysis of the Several Aspects of Job Satisfaction Between Different Occupational Groups. Boğaziçi Üniversitesi SBE Doktora Tezi, İstanbul.

Belias, D., Koustelios, A., Sdrolias, L., \& Aspridis, G. (2015). Job Satisfaction, Role Conflict and Autonomy of Employees in the Greek Banking Organization. Procedia-Social and Behavioral Sciences, 175, 324-333. https://doi.org/10.1016/j.sbspro.2015.01.1207

Bilen, A. (2008). Türkiye'de Muhasebe Mesleğinin Gelişimi ve Meslek Mensuplarının İş Tatmini Üzerine Bir Araştırma. Ankara: Gazi Kitabevi.

Bilgiç, R. (1998). The relationship between job satisfaction and personal characteristics of turkish workers. The Journal of Psychology, 132 (5), pp.549-557. https://doi.org/10.1080/00223989809599287

Burris, V. (1983). The social and political consequences of overeducation. American Sociological Review, 48 (4), pp.454-467. https://doi.org/10.2307/2117714

Büyüköztürk, Ş. (2011). Sosyal Bilimler İçin Veri Analizi El Kitabı (14. Baskı). Ankara: PEGEM Akademi. https://doi.org/10.14527/9789756802748

Çınar, O., \& Güney, S. (2012). Serbest Muhasebeci Mali Müşavirlerin (SMMM) Etik Algıları: Erzurum Örneği. Atatürk Üniversitesi İktisadi ve İdari Bilimler Dergisi, 26(2), 91-106.

Davis, K. (1984). İşletmede insan davranışı. (Çev. K. TOSUN vd.). İstanbul, İstanbul Üniversitesi İşletme Fakültesi Yayını.

Demirkol, O. F. (2018). Şanlıurfa İlindeki Muhasebe Meslek Mensuplarının Tükenmişlik Sendromlarının Tespitine Yönelik Bir Çalışma. Journal of Current Researches on Social Sciences, 8(1), 19-38.

Dizman, Ş., \& Güney, S. (2015). Muhasebe Meslek Mensuplarının Sorunları Kamu'da Karşılaşılan Olumsuzluklar ve Beklentiler: Erzincan İli Uygulaması. Akademik Sosyal Araştırmalar Dergisi, Y11, 3, 97-110.

Hacıhasanoğlu, T., \& Karaca, N. (2014). Bağımsız Çalışan Muhasebe Meslek Mensuplarının ve Muhasebe Çalışanlarının Tükenmişlik, İş Tatmini ve Stres Düzeylerinin Belirlenmesine Yönelik Bir Alan Araştırması. Süleyman Demirel Üniversitesi İktisadi ve İdari Bilimler Fakültesi Dergisi, 19(4), 153-170. 
Hackman, J. R., \& Oldham, G. R. (1975). Development of the Job Diagnostic Survey. Journal of Applied Psychology, 60(2), 159. https://doi.org/10.1037/h0076546

Hackman, J. R., \& Oldham, G. R. (1980). Work Redesign.

Herzberg, F. I. (1966). Work and the Nature of Man.

https://www.ismmmo.org.tr/Mevzuat/Kanun-Metni--142

Judge, T. A., \& Church, A. H. (2000). Job Satisfaction: Research and Practice. In Cooper, C. L. and Locke, EA (Eds.) Industrial and Organizational Psychology.

Kaygusuzoğlu, M., \& Uluyol, O. (2011). İşletme Yöneticilerinin Muhasebe Bilgilerini Kullanım Düzeyinin Araştırılması. Yönetim Bilimleri Dergisi, 9(2), 297-320.

Kısakürek, M. M., \& Alpan, N. (2010). Muhasebe Meslek Etiği ve Sivas İlinde Bir Uygulama. Muhasebe ve Finansman Dergisi, (47), 213-228. https://doi.org/10.25095/mufad.396750

Kutlu, H. A. (2008). Muhasebe Meslek Mensupları ve Çalışanlarının Etik İkilemleri: Kars ve Erzurum İllerinde Bir Araştırma. Ankara Üniversitesi SBF Dergisi, 63(02), 143-170. https://doi.org/10.1501/sbfder_0000002067

Maslow, A. H. (1943). A Theory of Human Motivation. Psychological review, 50(4), 370.

Mert, G., Dördüncü, H., \& İncaz, S. (2019). Dönüştürücü Liderlik Davranışlarının İş Tatmini Üzerindeki Etkisi: Vakıf Üniversitesi Örneği. Journal of International Social Research, 12(65). https://doi.org/10.17719/jisr.2019.3526

Nalbantoğlu, R. (2003). Muhasebe Uygulamaları Konusunda Meslek Mensuplarının Bakış Açıları. VI. Türkiye Muhasebe Denetimi Sempozyumu, 16-20.

Nalbantoğlu, Rıfat, (1997), "Meslek Mensuplarının Yetiştirdikleri Stajyerlerin Durumu", II. Türkiye Muhasebe Denetimi Sempozyumu, İSMMMO Yayınları No: 19, İstanbul. https://doi.org/10.26449/sssj.1566

Özkan, A., \& Özdevecioğlu, M. (2011). Muhasebe Meslek Mensuplarının Mesleki Streslerinin Ruhsal ve Fiziksel Sağl1kları Üzerindeki Etkileri. World of Accounting Science, 13(3).

Price, J. L., \& Mueller, C. W. (1986). Absenteeism and Turnover of Hospital Employees. JAI Press.

Şengel, S. (2011). Türkiye'de muhasebe meslek elemanı talebi üzerine bir araştırma. Muhasebe ve Finansman Dergisi, (50), 167-180. https://doi.org/10.18092/ulikidince.423439

Uzay, Ş. (2005). Muhasebe Meslek Stajyerlerinin Sorunlar1 ve Beklentileri: Bir Araştırma. Muhasebe ve Finansman Dergisi, (25), 70-78. https://doi.org/10.25095/mufad.396750

Vroom, V. H. (1964). Work and Motivation (Vol. 54). New York: Wiley.

Weiss, D. J., Dawis, R. V., \& England, G. W. (1967). Manual for the Minnesota Satisfaction Questionnaire. Minnesota Studies in Vocational Rehabilitation.

Weiss, D. J., Dawis, R. V., England, G. W., \& Lofquist, L. H. (1967). Minnesota Studies in Vocational Rehabilitation. Manual for the Minnesota Satisfaction Questionnaire, 22, 23-4. https://doi.org/10.1037/t08880-000

Yalçın, S. (2011). Muhasebe Meslek Mensupları ve İşletmelerin Etik Konusunda Tutumları: Türkiye Araştırması. Muhasebe ve Finansman Dergisi, (52), 47-66. https://doi.org/10.25095/mufad.579944 
Muhasebe Meslek Mensuplarının Çalışma Biçimlerine Göre; Genel İş Tatmini ve İş Tatmini...455

Yalçın, S. (2012). Muhasebe Meslek Mensuplarının Muhasebecilik Mesleğinin Geliştirilmesiyle İlgili Tutumlar1. Muhasebe ve Finansman Dergisi, (55), 113-136. https://doi.org/10.25095/mufad.396577

Yazıcıoğlu, İ. (2010). Örgütlerde İş Tatmini ve İşgören Performansı İlişkisi: Türkiye ve Kazakistan karş1laştırmas1. BİLIG, 55(1), 243-264.

Yereli, A. B. (2006). Muhasebe meslek mensupları anketi: mesleki profil, sorunlar, çözüm önerileri.

Yılmaz, O. \& Şahin, M.M. (2019). Çalı̧̧anların Eğitim Düzeyleri Üzerinden Sosyal Sermaye, Motivasyon ve İş Tatmini Arasındaki İlişkinin İncelenmesi; Batman Üniversitesi Çalışanları Üzerinde Bir Araştırma, Hoca Ahmet Yesevi Uluslararası Bilimsel Araştırmalar Kongresi (Gölbaşı Adıyaman) Tam Metin Kitabı. 